\title{
A CONSTRUÇÃO IMAGÉTICA BRASILEIRA: \\ O ANJO DA HISTÓRIA E A RESSIGNIFICAÇÃO DO \\ OLHAR ESTRANGEIRO NO BRASIL
}

\section{Daniele Cristina Liberato de Oliveira UERJ | UFPE Giselle Liberato Caetano de Souza UFPE}

\section{Resumo}

O objetivo deste trabalho é analisar Anjo da História, de Herbert de Paz, considerando elementos estéticos e as possibilidades de relação com uma produção cultural brasileira, ressignificada ao longo do tempo. A obra foi exposta na galeria do Centro Municipal de Artes Hélio Oiticica, pela exposição formAÇÃO 2016. Herbert de Paz é de origem de El Salvador e constrói sua obra dialogando a forma como ele começa a compreender a história brasileira e os conflitos contemporâneos por ele vivenciados, sendo, portanto, um olhar do estrangeiro para o Brasil. Neste sentido, este presente trabalho relaciona elementos da obra com possíveis interpretações de construção de memória coletiva, da história brasileira e da reprodutibilidade imagética como forma de pertencimento e reconhecimento da cultura de um povo.

\section{Palavras-chave:}

Ressignificação; Memória; Cultura.

\section{INTRODUÇÃO}

O objetivo deste trabalho é analisar a obra Anjo da História, de Herbert de Paz, sendo este um artista estrangeiro criando um objeto que, por sua essência, trata da construção do que artista considera como história do Brasil. Ao tratarmos dessa relação de representação estrangeira no Brasil, que se tornou bastante significativa, especialmente no século XIX, já seria um argumento que justificaria este trabalho, pois marca a transformação desse movimento de uso da imagem e de construção de brasilidade em pelo menos dois séculos da história recente do Brasil.

Contudo, o Anjo da História vai muito além disso. A obra se torna uma provocação por

\section{Abstract}

The aim of this work is to analyze Angel of History, by Herbert de Paz, considering aesthetic elements and the possibilities of relationship with a Brazilian cultural production, resignificance over time. The work was exhibited in the gallery of the Municipal Arts Center Hélio Oiticica, through the exhibition formACTION 2016. Herbert de Paz is from El Salvador and builds his work by dialoguing the way he begins to understand Brazilian history and the contemporary conflicts he experienced , therefore, being a look from abroad to Brazil. In this sense, this present work relates elements of the work with possible interpretations of building collective memory, Brazilian history and imagery reproducibility as a way of belonging and recognizing the culture of a people.

Keywords:

Resignificance; Memory; Culture.

diferentes aspectos. Ela se trata de colagem e de ressignificação de objetos artísticos, dos pontos significativos para compreensão da arte em sua contemporaneidade. O primeiro ponto trata de linguagem, e o segundo de seus conceitos, o que já torna sua interpretação com diferentes possibilidades de vertentes. Para o escopo desse artigo, no entanto, devido a complexidade de interpretações possíveis na obra do artista, atuaremos especificamente sobre a ideia do olhar estrangeiro e da construção de afetividade da memória coletiva, gêneros dos quais compõe um tratamento mais de aspectos da historiografia e se refere a uma parte do trabalho que desenvolvemos sobre a obra de Herbert. 
Sendo assim, discutiremos, brevemente, as questões sobre a construção de memória coletiva, no sentido principal de entender essa relação com as diferentes contribuições estrangeiras, que, de alguma forma, fizeram parte dos elementos culturais brasileiros. Neste sentido, trataremos da reprodução de determinadas imagens ao longo tempo, já que a obra de Herbert se refere a ressignificações e colagens de obras do século XIX, mas, para além desse processo, analisaremos como estes elementos se constroem no espaço/ tempo para a compreensão de cultura brasileira. A reprodutibilidade passa a ser o foco e demostra como as imagens vão sendo selecionadas e vão moldando o nosso olhar de consciência de memória coletiva.

\section{RESSIGNIFICANDO OBJETOS ARTÍSTICOS}

Tratar da imagem ao longo do tempo nos coloca diante do problema de como as imagens podem sobreviver, sendo reinseridas, recriadas e construindo sua própria história afetiva, memória psíquica, sendo, neste sentido, uma construção coletiva. Estes gestos são, em grande parte, concebidos antes dos objetos e ambos são associados a relações muito mais complexas do que as significações que podem, a priori, parecer-nos óbvias. Muito além disso: o que há além de uma imagem que se refere a uma outra que lhe anterior? Como o processo de apropriação imagética ressignifica a forma como compreendemos a imagem?

Essa compreensão de ressignificação na arte trata de certo movimento constante da imagem, onde ela não tem nem início nem fim. Essa forma de olhar para arte se afasta de historiografias em que o conhecimento é transmitido de forma linear, mas, ao contrário, coloca as imagens em um movimento de memória psíquica e coletiva. Essa circulação se refere justamente a encontros, movimentos e recepções, que se fortalece pela memória coletiva (WARBURG, 2005).

A memória coletiva é algo da vivência do indivíduo, porém ultrapassa o limite do pessoal, consegue alcançar as bases de uma vida comunitária e social, até chegar em uma consciência coletiva, mesmo que essa consciência seja algo que se passe como o cotidiano e não necessariamente a uma forma crítica de noção de sociedade. Muito longe disso. A memória coletiva passa ser algo tão presente, que sua reprodutibilidade garante a sua manutenção porque o mais importante, segundo Jessé de Souza, está em dois aspectos: a gênese e a reprodução ao longo do tempo. Essa ideia de comunidade compartilhada é fundamental para o fortalecimento de construção cultural de um determinado povo (SOUZA, 2009).

Ainda segundo Souza (2009), para a identidade nacional se legitimar era preciso quebrar os laços locais com um verdadeiro 'arsenal simbólico'. Um país só se legitimaria uma vez que construísse uma ideia de imaginário social nacional, onde cada indivíduo possa se reconhecer como parte do todo, que passa a 'ser 'internalizado' pelas pessoas comuns como algo 'seu', como algo indissociável de sua personalidade pessoal, para que possa lograr conquistar o coração e as mentes das pessoas comuns como todos nós" (SOUZA, 2009, p. 31). Entre outros aspectos deste processo está o conhecimento da história desse povo e a forma como ela é representada.

É dentro da cultura popular que teremos a força da reprodução desses elementos. Um simbolismo que se reproduz por repetição. Neste sentido, um outro conceito é significativo para esta pesquisa é de habitus, proposto por Pierre Bourdieu. O autor, a partir de uma abordagem de Erwin Panofsky, procurou deixar uma forma estruturalista implícita na visão levi-straussiana do inconsciente como uma imposição das formas simbólicas, colocando em evidência "as capacidades 'criadoras', activas, inventivas do habitus e do agente [...] embora chamando a atenção para a ideia de que este poder gerador não é de um espirito universal, [...] habitus [...] é um conhecimento adquirido e também um haver, um capital" (BOURDIEU, 1989, p. 61).

A incorporação do conceito de habitus bourdiesiana para o contexto brasileiro, pode ser interpretado, na visão de Souza (2003):

Como ancorada em instituições fundamentais, permite tanto a percepção dos efeitos sociais de uma hierarquia atualizada de forma implícita e opaca [...] quanto a identificação do seu potencial segregador e constituidor de relações naturalizadas de desigualdade em várias dimensões (SOUZA, 2003, p. 73).

Sendo assim, esses acontecimentos de formação de uma identidade brasileira não se deram tanto de forma clara, como de um tempo definido, 
mas dizem respeito a uma série de fatos, que gradativamente influenciaram neste processo. Para Cardoso (2016), o Brasil pode ser entendido, em sua formação cultural, como "um país onde qualquer golpe mequetrefe se arvora em 'revolução', mas onde as verdadeiras revoluções se processam quase em silêncio" (CARDOSO, 2016, p. 09), referindo-se ainda ao lento movimento das transformações culturais brasileiras. Isto significar dizer que diferentes acontecimentos lentamente foram moldando a forma como compreendemos o que é Brasil. $E$ a circulação de imagens, sobretudo, dentro da cultura popular, foram fundamentais para estruturar o olhar.

Há que salientar, todavia, que muito do imaginário estético presente no repertório visual da história do Brasil nem sempre foi produzida por brasileiros. Construímos muito dessa referência de memória coletiva nacional, tomando como base elementos estéticos que foram sendo apresentados por olhares de muitos estrangeiros, criando, assim, perspectivas desses elementos culturais brasileiros. Esse movimento poderia parecer algo ímpar da história ligado a acontecimentos que permearam a história do Brasil, ao longo do século XIX. Veremos, no entanto, que ainda é muito pertinente nos dias de hoje.

Não é algo novo saber que a produção da arte brasileira alavancou muitos aspectos do olhar do colono. Diversas pinturas sobre o cotidiano das cidades, assim como grandes pinturas de paisagem, fizeram parte de um trabalho de retratar o Brasil como um país abundante de riquezas naturais e com boa mão de obra escrava. A construção identitária artística do século XIX, nesse primeiro momento, era de um país dependente de seu colonizador e que tampouco tinha perspectiva de se libertar, um país que seria o provedor de matéria-prima para os países colonos e nada mais além disso.

Os exemplos são múltiplos em diferentes linguagens da produção artística brasileira. Na pintura, Debret representava o cotidiano caótico da época, com ruas apinhadas de gente, sejam escravos ou colonos, cada um dividindo o espaço seja para trabalhar, seja para realizar passeios especialmente na capital do país. Algumas pinturas representavam o processo de extração de matérias primas, feitas por escravos, reforçando a ideia de um país que possuía uma inesgotável fonte de riquezas, além de demonstrar as hierarquias sociais que foram estabelecidas. No início do século XIX, as pinturas de paisagem também começaram a ganhar espaço. Pintores como Felix-Emile Taunay pintavam cada vez mais a cidade mesclada a paisagem, em uma tentativa de comprimir na pintura tudo o que a cidade poderia oferecer de melhor. Com o advento das rotundas, as pinturas de paisagem ganharam grande destaque e circularam na Europa representando o olhar das cidades brasileiras (HERMANN, 2013).

Já na literatura ou na música, ainda no século XIX, temos mais uma vez a representação de um país com uma rica natureza através do hino nacional, por exemplo. É possível perceber em muitos versos o quanto o elemento da terra é demarcado como a mais rica ou de campos mais lindos e possuidor de mais flores. Posteriormente, Gonçalves Dias se referiu ao Brasil como uma terra de muitas palmeiras, dando a impressão de que a natureza do país fosse incomparável. Há que se destacar, ainda, neste campo, a reprodução da ideia do índio sendo romantizado, assim como da construção do sertão. Todo o imaginário de um país sendo construído por meio de mídias de entretenimento, que posteriormente circularam pelo mundo.

Esses são só alguns exemplos do que estava sendo produzido durante todo o século XIX. No século seguinte, diversos livros, tais como Os sertões, de Euclides da Cunha ou Macunaíma, de Mário de Andrade, exploravam a imagem de um sertão pobre e com guerra, espalhando uma identidade de um povo que precisa lutar para sobreviver no dia a dia. Sendo assim, ao longo dos séculos, o país foi retratado de formas diversas. De pinturas de paisagem e históricas a poemas e livros regionalistas, todos contribuíram para a construção de uma identidade dita brasileira. A construção da identidade de um povo, que, por sua vez, é denominado como sendo um povo cordial, de sorriso fácil e de um país com belezas naturais inestimáveis. Quem seriam então, os agentes que possibilitaram a construção desse imaginário popular?

Pinturas, poemas, cartas das mais diversas, canções, livros, tudo o que era produzido ao longo do tempo foi ajudando para a construção de uma identidade nacional. Não se esquecendo que essa 


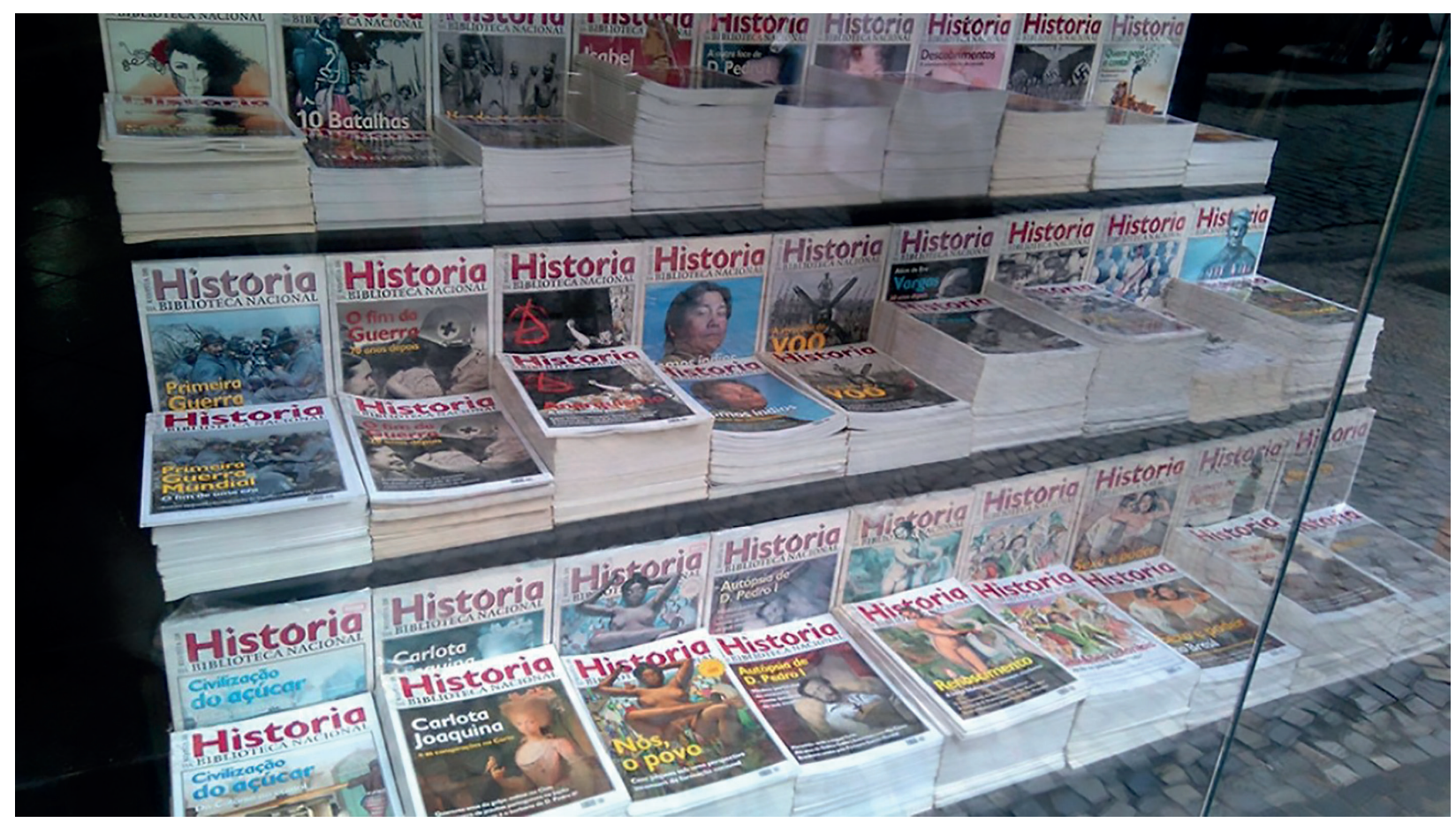

Figura 1 - Registro fotográfico do Artista Herbert de Paz sobre Revista de História da Biblioteca Nacional

Fonte: Acervo privado de Herbert de Paz. Cedido pelo artista.

construção teve, em um primeiro momento, o contato do olhar de estrangeiros, que relatavam em suas obras elementos culturais que os mesmos observavam no cotidiano do Brasil.

\section{O ANJO DA HISTÓRIA}

A obra analisada, no presente trabalho, foi exposta pela primeira vez na galeria do Centro Municipal de Artes Hélio Oiticica, pela exposição "formAÇÃo 2016". Apesar do nome, a exposição foi realizada no ano de 2017 e tinha essa atribuição porque se tratava do trabalho final dos alunos de graduação em artes visuais do Instituto de Artes da Universidade Estadual do Rio de Janeiro - UERJ. A exposição teve a curadoria de Alexandre Vogler e Maria Moreira. Ela é objeto de uma colagem aplicada diretamente na parede na proporção de $120 \times 230 \mathrm{~cm}^{1}$.

O artista Herbert de Paz é de origem do país de El Salvador. Veio para Brasil em 2013, para a graduação em artes visuais, no instituto descrito acima, a partir do Programa de EstudantesConvênio de Graduação (PEC-G). Este programa é estabelecido entre países em desenvolvimento com os quais o Brasil tem acordos de apoio educacional e cultural. O programa, segundo a portaria do MEC, foi criado em 1965, pelo Decreto $n^{0} 55.613$, hoje atualizado pelo Decreto $n^{0}$ 7.948. 0 aluno estrangeiro deverá comprovar ter diploma de Ensino Médio ou equivalente, proficiência em língua portuguesa, garantir que poderá custear sua estadia no Brasil e seu retorno ao seu país de origem após o término do curso de graduação, contribuindo com sua nova formação para o desenvolvimento de seu país (Ministério da Educação, 2018).

Quando chegou ao Brasil, para se habituar a história do país, Herbert começou a fazer constante leitura de uma revista chamada Revista de História da Biblioteca Nacional, conforme Figura 1. Com base nestas leituras, o artista foi apresentado a um arsenal simbólico de história do Brasil, construído a partir da reprodução de pinturas de outros artistas ao longo do século XIX contidos nas páginas da revista. Muitos destes artistas estrangeiros, como Herbert.

A partir de uma imagem específica encontrada em uma destas revistas, Herbert começou a construir a obra O Anjo da História. Trata-se de uma pintura de artista desconhecido, chamada de 'Ama com a criança ao colo - Catarina e o Menino Luis Pereira de Carvalho', pertencente a coleção do Museu 


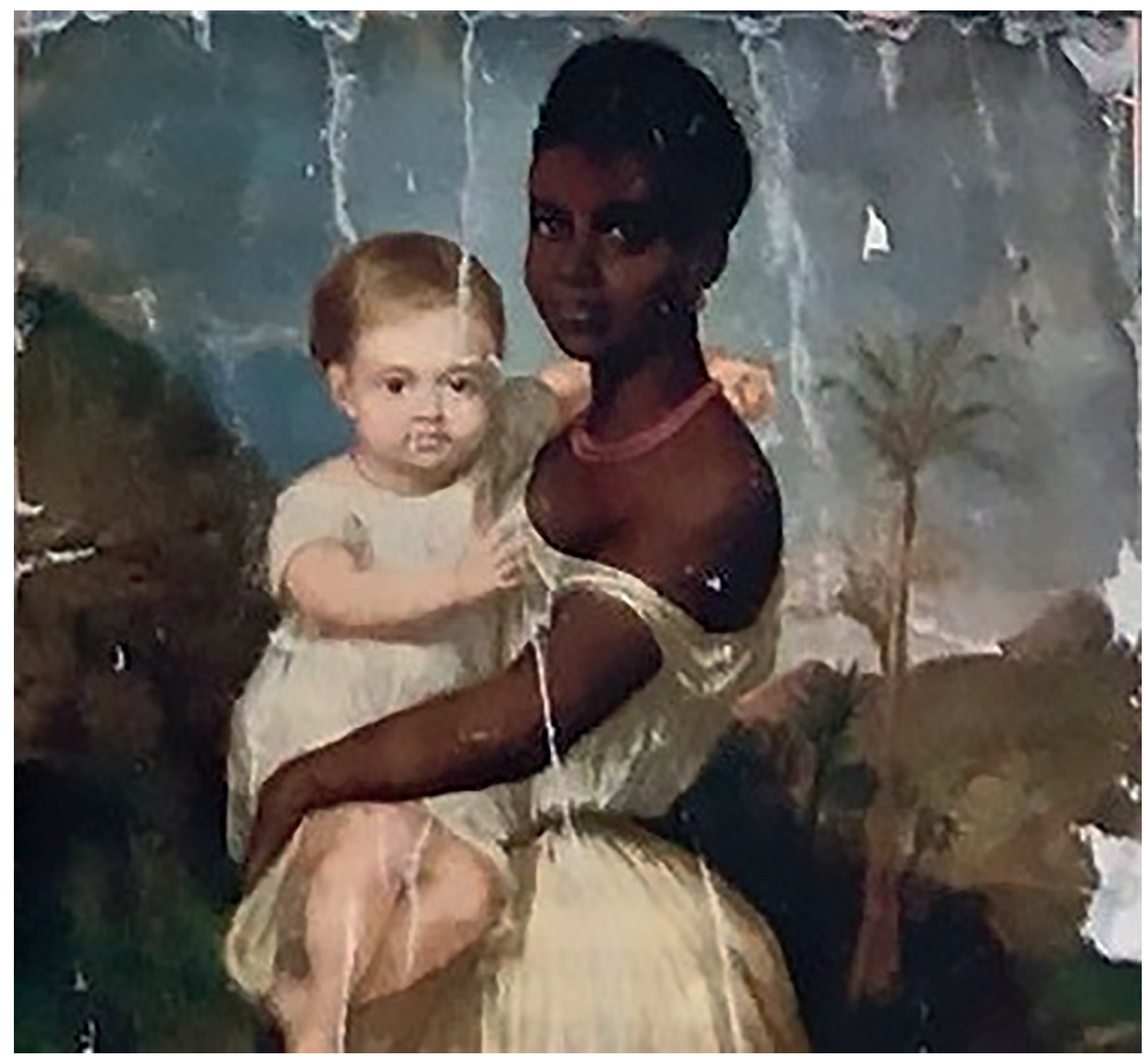

Figura 2 - Recorte de artista Herbert de Paz de Revista de História da Biblioteca Nacional da obra 'Ama com a criança ao colo - Catarina e o Menino Luis Pereira de Carvalho', Museu Imperial de Petrópolis. Fonte: Acervo privado de Herbert de Paz. Cedido pelo artista.

Imperial de Petrópolis. Segundo Maria Elizabeth Ribeiro Carneiro, a pintura está exposta no quarto da Princesa Isabel sem assinatura ou datação, apenas com a informação de óleo sobre tela e o título 'Mucama com Criança no Colo'. Em contato com setor de Museologia do Museu, ainda segundo a autora, há uma correspondência datada em "24 de julho de 1977, onde Heloisa Machado Sobrinho informava tratar-se de Luís Pereira de Carvalho, (...) que aparece no colo de sua mucama de nome Catarina, um presente da madrinha do retratado, D. Maria Isabel de Jesus Vieira, mãe do barão de Aliança" (CARNEIRO, 2009, p. 10).
Carneiro (2009) destaca que até 1977 a obra era tratada como sendo 'Retrato de D. Pedro II' - talvez por isso esteja exposta em local privada da Família Imperial. Porém, após essa correspondência, a pintura passou a ser associada à mucama Catarina e a figura de Luís Pereira de Carvalho em sua infância. Tratar dessa imagem já seria por deveras muito significativo para pensar o olhar e a representação do imaginário brasileiro, do lugar escravizado, da relação das amas de leite, da exposição do corpo feminino da mulher afrodescendente. Mas, o presente trabalho, para direcionar essa análise, irá atuar mais diretamente ao processo de ressignificação 


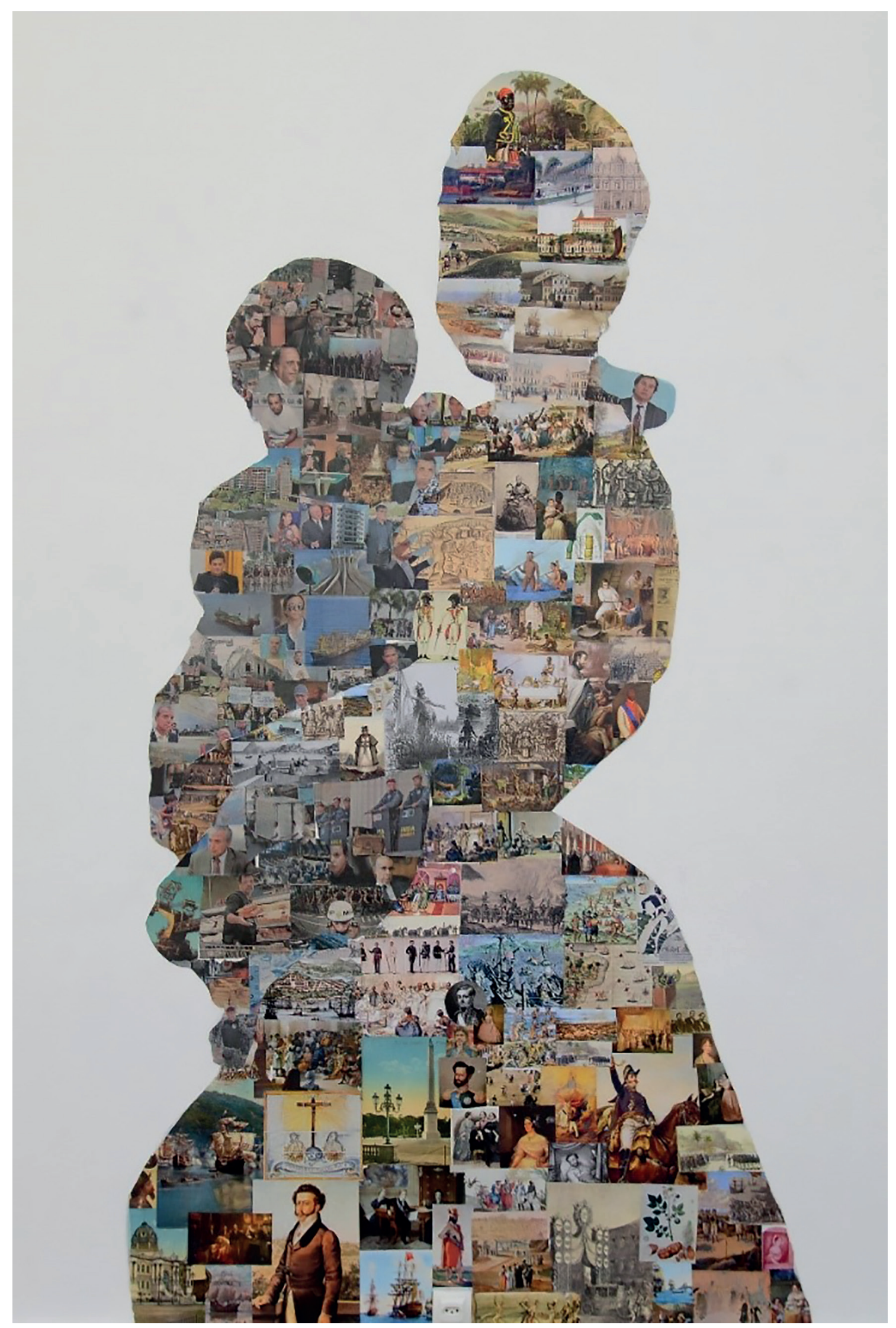

Figura 3 - O Anjo da História, Herbert de Paz, Colagem, 120 × 230 cm, exposição formAÇÃO 2016 (realizada em 2017), Centro Municipal de Artes Hélio Oiticica Fonte: Acervo privado de Herbert de Paz. Cedido pelo artista. 


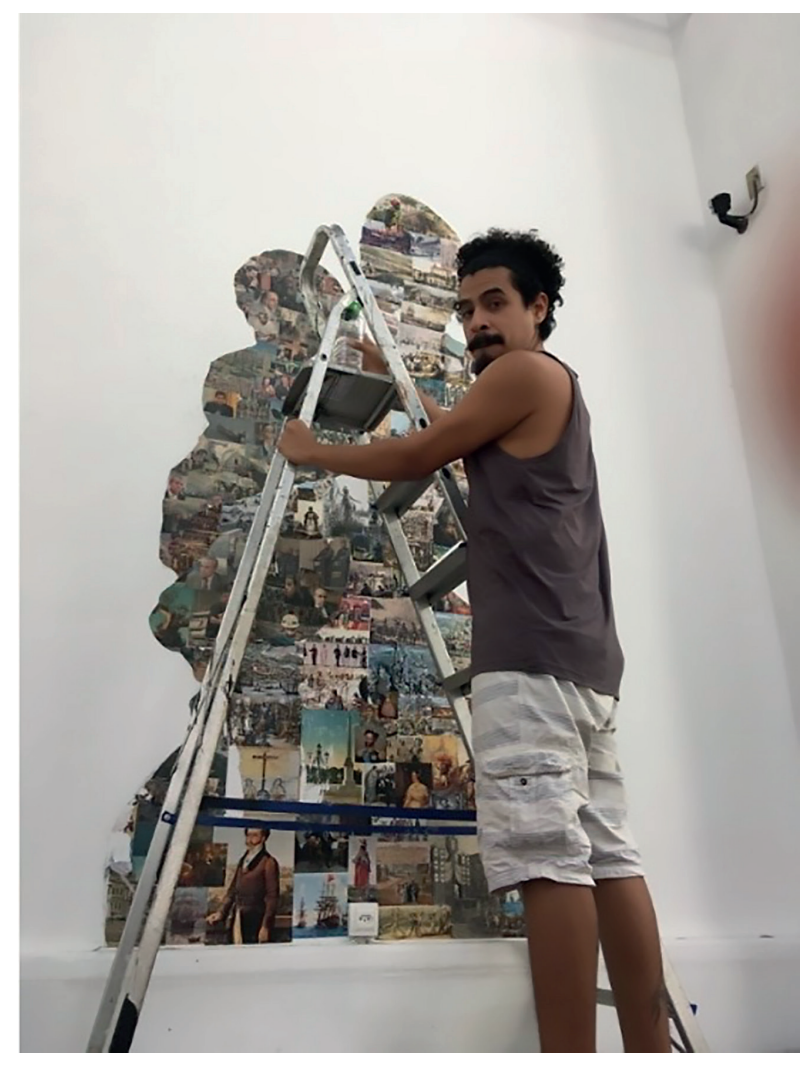

Figura 4 - Trabalho de artista Herbert de Paz em aplicação de colagem de $O$ Anjo da História em parede de galeria de Centro Municipal de Artes Hélio Oiticica

Fonte: Acervo privado de Herbert de Paz. Cedido pelo artista.

que esses diferentes olhares traçam ao longo do tempo. Da imagem encontrada na Revista História da Biblioteca Nacional, de uma representação do século XIX, conforme Figura 2, Herbert da Paz vai começar a moldar o seu olhar sobre a obra e o cotidiano brasileiro do século XXI.

A obra O Anjo da História foi construída pelo artista seguindo a silhueta estética proposta pela obra 'Ama com a criança ao colo - Catarina e o Menino Luis Pereira de Carvalho'. A partir dela, o artista criou duas perspectivas de construção histórica do Brasil: a primeira contornando o corpo da mucama, só com recortes Revista de História da Biblioteca Nacional, onde ele acreditava se tratar das escolhas de linha histórica do Brasil. Os recortes vão traçando uma linha de tempo de cima para baixo, isto é, da cabeça para seguimento do corpo, passando das primeiras cenas de colonização portuguesa até eventos retratados do governo Imperial. A segunda parte, porém, se trata de recortes de jornais da recente história política do Brasil, com ênfase na operação Lava Jato, um grande movimento de investigação política, que estava em voga no Brasil no período de construção da obra, como pode ser visto na Figura 3.

Em tamanho de $230 \mathrm{~cm}$, isto é, em tamanho quase colossal, o artista aplicou sua colagem já diretamente na parede da galeria de artes em que a obra foi exposta, conforme Figura 4. Sendo assim, o artista estaria, neste caso, criando dois ambientes, um de orientação histórica, outro da atualidade dos acontecimentos políticos que ele, quanto estrangeiro, estava vivenciando no Brasil. É preciso destacar que as escolhas de cada recorte para compor o todo da obra vai sendo moldado das perspectivas que Herbert vai tomando dessa nova sociedade que lhe é apresentada.

Algumas cenas podem ter se dado por aspecto de surpresa, outras por curiosidade. O que fica claro é que se Herbert tivesse vivenciado essas histórias quanto parte de memória coletiva, possivelmente suas escolhas seriam diferentes. Está aí o recorte de várias narrativas em que o artista vai moldando, ora pelo caminho da história, ora pelos acontecimentos políticos, se delineando pela própria silhueta da arte que ele cria pela colagem. A própria figura da 'Ama com a criança ao colo - Catarina e o Menino Luis Pereira de Carvalho' aparece retratada na colagem, conforme Figura 5.

A posição em que a 'Ama com a criança ao colo' aparece retratada é muito significativa para o artista: ela se encontra em um ponto de passagem do corpo da mulher, quase um ponto de encontro entre ela e o menino que vem ao seu colo. Além disso, ela era é representada ao lado de outra mulher afrodescendente com uma criança branca ao seu colo. A mulher que se apresenta ao seu lado, no entanto, não tem o seu corpo exposto como o caso de Catarina, ela usa vestes bem distantes daqueles a que se destinam os escravos no Brasil do século XIX. Acima, há duas cenas, uma de um grupo indígena, outra de um grupo de matriz africana, cenas de tipos de encontros entre esses grupos.

Como dito, anteriormente, a disposição da colagem de Herbert se dá em uma linha histórica de cima para baixo, da colonização ao país imperial. Na Figura 5, é possível observar detalhes da representação no rosto da ama, todas pinturas 


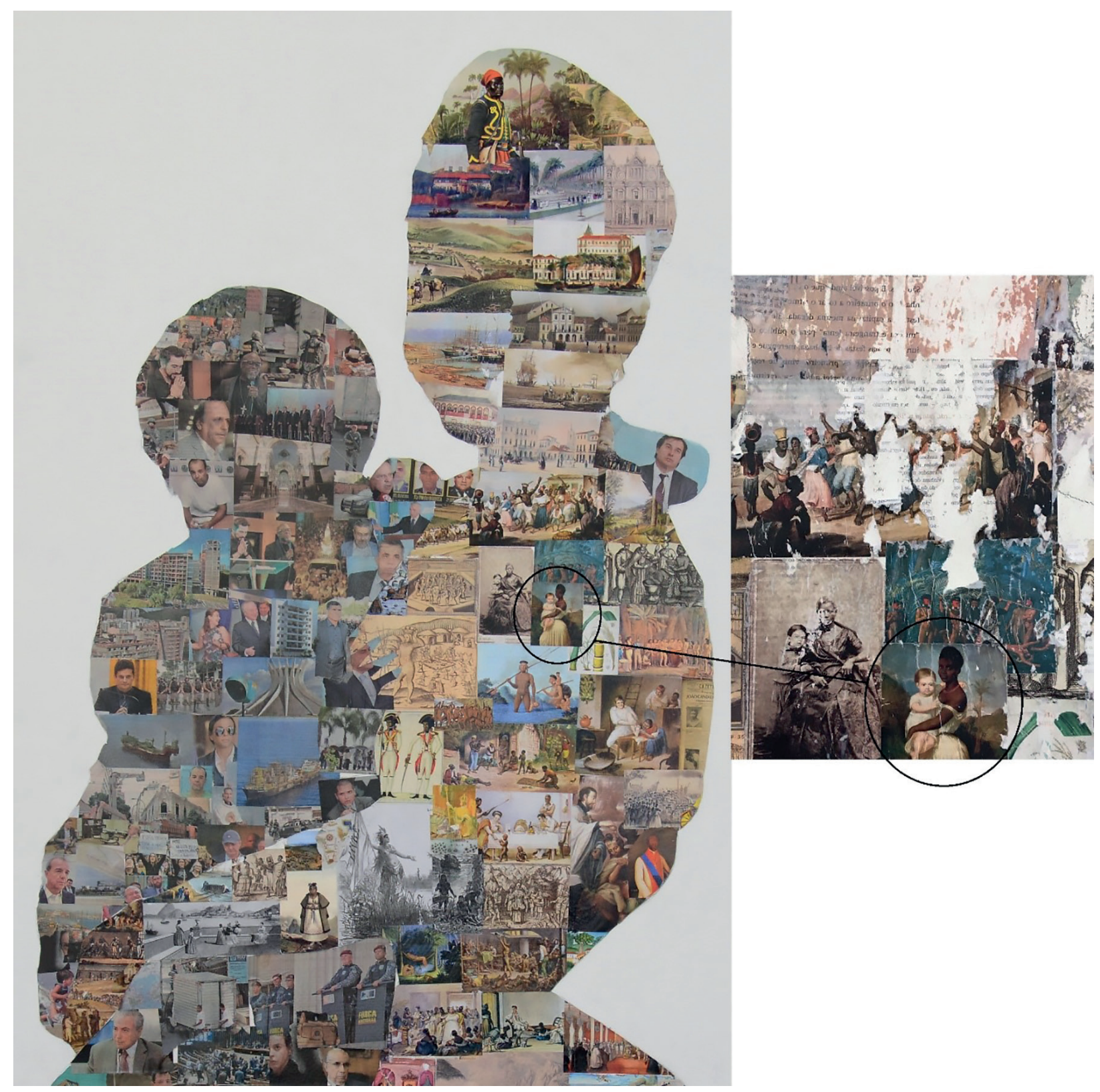

Figura 5: Destaque para colagem de 'Ama com a criança ao colo - Catarina e o Menino Luis Pereira de Carvalho' em O Anjo da História, de Herbert de Paz. Fonte: Acervo privado de Herbert de Paz. Cedido pelo artista.

de paisagens e de cidades, onde só aparece uma figura humana em uma colagem sobreposta. Uma figura militar negra destacada pelo artista. É interessante ressaltar essa relação, portanto, do início do Brasil marcado pelas características naturais, tais quais destacamos anteriormente neste trabalho. Em um primeiro olhar, o fruidor da obra poderia imaginar uma colagem meramente de pinturas das quais o artista foi se afeiçoando. Mas, quando observamos mais fixamente é possível identificar que Herbert passa por três linhas de tempo: a primeira colagem, na região do rosto, com pinturas se tratando de paisagismo brasileiro; na região intermediária do corpo destacando-se a vida cotidiana nas cidades, muitas vezes de elementos de grupos africanos, em especial cenas da escravidão.

Por fim, na base da ama, em um terceiro momento, trata-se do período imperial brasileiro, com muitos retratos dos imperadores que marcam outra passagem da arte academicista brasileira, isto é, estaria representando o advento do gênero dos retratos, mas, neste caso, sobretudo, utilizado para o fortalecimento e a legitimação da imagem imperial. Herbert fez algumas colagens 
de presidentes de período atual quase paralelos a esses retratos imperiais na região do braço do menino, como destaque desse processo de legitimação política, ao mesmo tempo que o critica, já que a maioria das reportagens contemporâneas destacadas por ele são de investigações acerca da autenticidade e legitimação política, isto é, os elementos da corrupção brasileira que parecem ter marcado o olhar do artista. Sendo assim, cenas do cotidiano atual de legitimação política se apresentam de forma paralela aos primeiros governos de um Brasil independente.

Vale ressaltar que um aspecto importante que tratamos no início deste trabalho foi sobre a relação da memória coletiva, da consciência de história de um povo, da internalização das imagens como arsenal simbólico que permite uma ideia de pertencimento; enfim, diferentes aspectos que permite que um povo se identifique como nação. Quando trazemos para escopo desse trabalho o Anjo da História, todos esses aspectos estão de alguma forma envolvidos. Primeiro, a revista do qual Herbert faz os seus recortes, se trata de uma publicação cuja intensão era apresentar a história do Brasil de maneira imagética.

Sendo assim, a própria revista se trata, concluímos, de algo que pretendia por essência construir a sua história, alavancando determinadas obras que seus editores consideravam mais significativas, isto é, uma seleção que dava protagonismo a certa produção artística em detrimento de outra, sob o alicerce de se falar de história. Neste caso, podemos considerar que estamos falando de três aspectos de formação do olhar: a 'Ama com a criança ao colo - Catarina e o Menino Luis Pereira de Carvalho', realizada por um artista desconhecido provavelmente estrangeiro, a Revista de História da Biblioteca Nacional e o Anjo da História, este último, porém, acaba sendo muito atrelado ao movimento dos dois processos anteriores.

Neste sentido, Herbert cria uma forma de representar a história do Brasil, que poderia ser contada de formas diferentes, mas não deixa de passar pela própria reprodutibilidade de uma estética brasileira que lhe é anteriormente apresentada. O que deixa à margem outros processos históricos que não passam pelo seu olhar. Talvez uma vista rápida por Anjo da História pudesse parecer que o mesmo movimento do
Brasil ser representado por estrangeiros que ocorreu no século XIX, ainda se torna vigente e de alguma forma é reproduzido no século XXI. Mas, Herbert, apesar estrangeiro, está sendo apresentado a um conjunto imagético, um arsenal simbólico, que faz parte de uma memória coletiva construída. O artista a interpreta. Neste ponto, temos o elemento de seu olhar e de aspectos que podem lhe surpreender mais do que outros.

Há uma linha tênue, portanto, de sermos vistos de fora como a interpretação de elementos que fazem parte dessa memória coletiva brasileira e a própria reprodutibilidade de uma construção de memória coletiva pré-estabelecida por uma revista consagrada da história brasileira. Poderíamos, por exemplo, destacar que não há a reprodução de trabalhos indígenas e de matrizes africanas como base da história brasileira. Os grupos de origem africana são reproduzidos pela sua opressão escravocrata e não pelo seu olhar de produtor quanto artista. Eles são contatos, não produtores. Não que a opressão não seja importante, claro que é. Mas, não há espaço para que esses grupos contem sua história do ponto de vista delas próprias.

A sensação é que o Anjo da História traz, concluímos, toda essa complexidade. Herbert vai moldando e nos provocando a repensar toda a construção e reprodução das imagens que constroem uma ideia de história do Brasil. Vale ressaltar, ainda, a posição da história apresentada, separadamente, na reprodução da mulher afrodescendente, enquanto a crise política do século XXI está presente no desenho de colagem do menino branco, outra importante provocação do artista. Consideramos esse aspecto um adendo: o século XXI tem sido um momento história de muita disputa entre as chamadas minorias por espaço dentro desse todo da identidade nacional.

A tensão entre essa crise identitária, no entanto, ainda é conflitante. Ao colocar as imagens tidas como ideais e desconsiderar essa produção das minorias dentro do espaço institucionalizado da arte, Herbert destaca, mesmo que de forma sinuosa, o lugar não institucionalizado das próprias pessoas ali representadas. Nesse sentido, consideramos, que a provocação do menino branco na história recente do Brasil acaba sendo mais um elemento que pode nos 
fazer questionar se no final muitos aspectos que moldaram a identidade brasileira continuam estão sendo reproduzidas ao invés de questionadas, muito embora a intensão do artista, inicialmente, fosse representar a criança na atualidade como a ideia do novo tempo.

Em termos de linguagem, também podemos destacar como uma característica marcante nessa obra. Enquanto 'Ama com a criança ao colo - Catarina e o Menino Luis Pereira de Carvalho' permeia as formas estéticas mais idealizadas do século XIX, especialmente dentro do movimento academicista, a revista usada por Herbert circula pelo meio do cotidiano das pessoas que consumiam esse tipo de leitura e sua circulação alcançou até os dias atuais e, por fim, o artista usa de colagem para executar a sua obra. Temos em destaque, portanto, três formas diferentes de circulação: o academicismo, o cotidiano popular das publicações e a colagem, linguagem de uma fase moderna da arte.

Como colocado no início deste presente trabalho, é justamente no campo da cultura popular que este 'arsenal simbólico' de pertencimento de um povo, como nos apresenta Souza (2009), acaba ganhando forma e se fortalecendo, o que ressalta novamente que, quando Herbert faz sua obra a partir de recortes da revista, está de alguma forma reproduzindo a reprodutibilidade imagética proposta para construção da identidade cultural brasileira ao longo do século XX. Acrescenta o seu olhar, sua estética, sua produção artística, mas a reprodutibilidade está ali presente.

Sendo assim, em um primeiro momento, a relação da ama do século XIX e a colagem do século XXI poderíamos parecer mais relevante. Mas, é justamente a criação do arsenal simbólico dentro do cotidiano e os elementos trazidos por Herbert delineados de diferentes formas em seu trabalho, que fazem dessa obra uma provocação sobre como a identidade brasileira foi construída, consagrando assim o seu trabalho nessa linha do tempo.

\section{CONCLUSÕES}

Iniciamos esse processo de pesquisa falando sobre a importância das imagens na criação do lugar de pertencimento: o que há além de uma imagem que se refere a uma outra que Ihe é mais antiga? Como as imagens podem sobreviver, ser reinseridas, recriadas e construindo sua própria história afetiva? Ao tratar de O Anjo da História, tema central dessa pesquisa, estamos lidando com a construção do olhar do artista sobre a história do Brasil e percebemos que cada escolha se trata da forma como o artista concebeu sua percepção do país. Essa percepção, no entanto, está associada a reprodutibilidade de uma revista sobre a construção de história brasileira a partir da arte.

Vale ressaltar, ainda, que a obra original, apesar de pertencer a um artista desconhecida, foi realizada em um período em que muitos artistas estrangeiros estavam atuando no Brasil. Do olhar do século XIX para a pintura, para a colagem no século XXI, quase 200 anos depois de um olhar de fora para dentro. Além disso, Herbert cria uma estética que segue uma silhueta do corpo da mulher e outra pelo corpo do menino. Em perspectiva, as diferenças de tipos de colagem destacam os coloridos das obras que vieram das revistas, para aquelas que vieram de jornais. O efeito estético não deixa de ser sinuoso, independentemente de seu conteúdo.

Mas, as escolhas recriam a própria história do Brasil. Definir uma pintura a outra para quem não cresceu neste país, em que muitas destas pinturas poderiam folhear seus livros didáticos do ensino regular fundamental e médio de história do país, tem grande significado, uma vez que este arsenal simbólico não tinham uma construção preliminar de imagens da história tidas como ideais. Herbert pode criar livremente o que gradativamente suas leituras e vivências foram Ihe apresentando.

A colagem ainda mescla com uma história recente do país na figura de um menino. É paradoxo pensar que a mulher constrói a história e o menino a atualidade. A mulher é afrodescendente e carrega o menino. O menino era uma criança branca, que posteriormente se tornou uma figura iminente no Brasil. Ela, uma mulher, que porventura sabemos seu nome. Ele, um homem, com nome e sobrenome. Mas, ela o ampara. A história segura a presença contemporânea, simbolicamente, e estes elementos são provocados pelo artista, repensando as linhas de tempo e de construção imagética de identidade brasileira sobrepostas em sua colagem. 


\section{NOTAS}

1. Os dados apresentados neste item referem-se a visita in loco das autoras desse artigo durante o período de exposição da obra.

\section{REFERÊNCIAS BIBLIOGRÁFICAS}

BOURDIEU, Pierre. 0 poder simbólico. Trad. Fernando Tomaz. Lisboa: DIFEL, 1989.

CARDOSO, Rafael. 'Prefácio'. In.: FONSECA, Letícia Pedruzzi. Uma revolução gráfica. Julião Machado e as Revistas Ilustradas do Brasil, 1895-1898.São Paulo: Blucher, 2016.

CARNEIRO. Maria Elizabeth Ribeiro. Imagens de mulheres negras, arte e poderes em circulação no Brasil oitocentista. Fortaleza: ANPUH - XXV Simpósio Nacional de História, 2009.

HERMANN, Carla. Considerações sobre dois panoramas viajantes do Rio de Janeiro no século XIX. $n^{\circ}$ 07. Rio de Janeiro: Revista do Arquivo Geral do Rio de Janeiro, 2013, p. 105117.

PEC-G. Brasília: Ministério da Educação, 2018. Disponível em: 《< http://portal.mec.gov.br/ pec-g $>$. Acesso em 28 de maio de 2020.

SOUZA, Jessé. A Ralé Brasileira: Quem é e Como Vive. Belo Horizonte: Editora UFMG, 2009.

SOUZA, Jessé de. (Não) Reconhecimento e subcidadania, ou o que é ser gente? Lua Nova [online], 2003.

WARBURG, Aby. Imagens da região dos índios Pueblo da América do Norte. Trad. Jason Campelo. Ano 6. v. 1. no 8. Rio de Janeiro: Concinnitas, 2005.

\section{SOBRE AS AUTORAS}

Daniele Cristina Liberato de Oliveira é doutoranda do Departamento de Arte da UERJ e doutoranda do Departamento de Arqueologia da UFPE.

Giselle Liberato Caetano de Souza é graduanda do Departamento de Arte da UFPE. 